\title{
Free Radical Scavenging Activity of Five Benzoic Acid Derivatives: A Theoretical M06-2X Study
}

Bienfait Kabuyaya Isamura *, [a], [b], Issofa Patouossa [c], Isaac Kaba Elaka [d], Aristote Matondo ${ }^{[b]}$, and Pius Tshimankinda Mpiana *, [b]

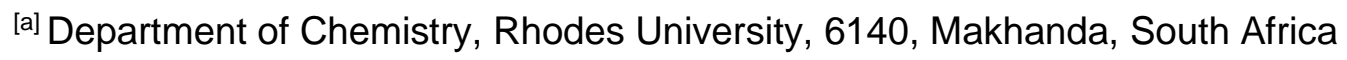

[b] Department of Chemistry, Faculty of Sciences, University of Kinshasa, Kinshasa XI, Democratic Republic of the Congo

[c] Physical and Theoretical chemistry unit of the Laboratory of applied Physical and Analytical Chemistry, Faculty of Sciences, University of Yaoundé I, Yaoundé , Cameroon

${ }^{\text {[d] }}$ College of Pharmacy and Pharmaceutical Sciences, University of Toledo,Toledo, Ohio, USA 


\section{Abstract}

The meta hybrid M06-2X functional combined with the $6-311++G(d, p)$ basis set are used to investigate the antioxidant activity of five benzoic acid derivatives naturally occurring in several plant food: gallic acid, para-hydroxybenzoic acid, protocatechuic acid, syringic acid and vanillic acid. To assess the antioxidant properties of these compounds, three mechanisms of free radicals scavenging are considered, namely the hydrogen atom transfer (HAT), stepwise electron transfer proton transfer (SET-PT) and sequential proton loss electron transfer (SPLET) models. The effect of polar environments on the antioxidant power of these compounds is mimicked in water and methanol using the IEFPCM solvation method. Our findings suggest that HAT is the preferred mechanistic pathway in gas phase, while SPLET is favoured in polar mediums. Protocatechuic and gallic acids are the most active in gas and polar solutions respectively, whereas PHBA is the least active in all the environments considered. The $\mathrm{O}-\mathrm{H}$ group in para position of the carboxylic group ( $\mathrm{O} 3-\mathrm{H}$ for $\mathrm{GA}$ and $\mathrm{O} 2-\mathrm{H}$ for the rest) is confirmed to be the most reactive site in gas phase, while in solution it is either of the $\mathrm{O} 1-\mathrm{H}$ site (for PHBA, PCA, SA and VA) or O4-H groups (for GA). The "HOMO-rule" of free radical scavenging ability does not seem to account properly for the antioxidant properties of this set of chemicals.

Keywords: Antioxidant activity, HAT, SET-PT, SPLET, frontier molecular orbital 


\section{Introduction}

The human body is an excellent autonomous machine where an uncountable number of reactions take place every second to maintain life. Under certain conditions, specific metabolic reactions may produce very reactive entities bearing an unpaired electron and free to move throughout the body [1]. For example, it is known that viral infections tend to stimulate the production of free radicals [2]. When released in small amounts, free radicals are often beneficial to the body as they are involved in oxygen-dependent reactions and aerobic respiration [3]. In this first character, free radicals are friendly products of normal cellular metabolism and play incredible roles in the immune defense system, in several cellular signaling pathways, in mitogenic response as well as in redox regulation [4]. However, due to their strong oxidative character, excessive amounts of free radicals may get out of control and cause severe damages to biological macromolecules such as lipids [5], proteins [6], and DNA [7], which may ultimately lead to apoptotic or nectrotic cell death [8].

Dangerous free radicals are often annihilated in the body thanks to an automatic response mechanism relying on the presence of molecules called antioxidants. These molecules exhibit the ability to scavenge free radicals and alleviate the damage provoked by these "hot" chemical entities [9]. Normally, a balance between free radicals and antioxidants is necessary for adequate physiological function. If free radicals become greater than the ability of the body to control them, this gives rise to a situation known as oxidative stress [10], which favors the development or acceleration of many deadly diseases such as Alzheimer's disease [11], cancer [12], and liver fibrosis [13]. In case the human body seems not to be producing enough antioxidants, the recommendation is to supply it with external sources of antioxidants on a regular basis to maintain the equilibrium and tackle the oxidative stress. It must be noted that many antioxidants occur naturally in plants [14][15][16][17][18], animals [19][20], and microorganisms [21][22] or may be synthesized by chemical means [23][24]. Thus, with the perpetual need to identify more effective 
antioxidant candidates to integrate into the preventive or therapeutic pipeline of several pathologies, the isolation and synthesis of new antioxidants is a hot research domain attracting the interest of a myriad of scientists [25][26][27][28].

During the past decades, a number of studies have excellently documented the antioxidant activity of benzoic acid derivatives and many more investigations are still popping up [29][30][31][32]. Following the same trend, we report in the present study an in-silico investigation of the antioxidant power of five benzoic acid derivatives including gallic acid (GA), parahydroxybenzoic acid (PHBA), protocatechuic acid (PCA), syringic acid (SA), and vanillic acid (VA) (Figure 1).
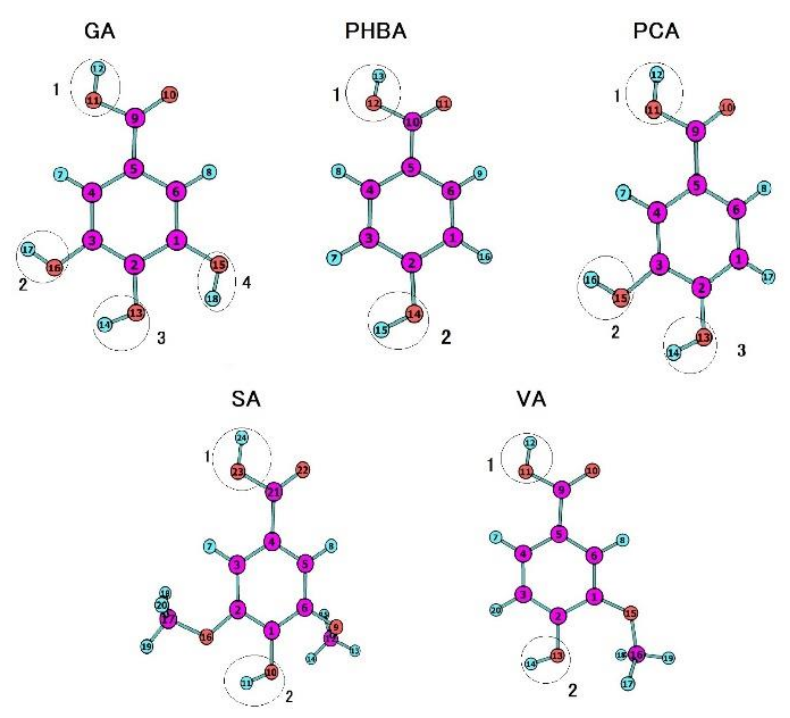

Figure 1. Schematic representation of the five compounds investigated, as well as the atomic numbering and active site ( $\mathrm{OH}$ groups) labelling considered in this study

It is worth noting that all of these compounds are present in plant food where they usually occur in bound form as components of complex structures like lignins and hydrolysable tanins, or attached to cell walls and proteins [33][34]. Although these molecules have been the subject of separate previous works [35][36], the present study draws its peculiarity from the fact that it involves all of them in a comparative discussion of their antioxidant activity in gas and polar phases at the M06-2X/6-311++G(d,p) level, and following three different mechanisms of free 
radical scavenging. The antioxidant activity of each compound is assessed using thermodynamic parameters defined with respect to each mechanism. Then, the collected data are used to discuss the most preferred pathway in each environment, before inferring the most likely order of free radical scavenging activity. Note that spin densities and frontier molecular orbitals are computed to get insight into the global and local reactivity of the five compounds.

\section{Methodology}

\subsection{Mechanism of free radical scavenging activity}

Three main mechanisms have been advanced to explain the free radicals scavenging action of (poly)phenolic antioxidants. Although the net result of the three mechanisms is the same, i.e. the formation of less harmful radicals, it is possible that under certain conditions one of the possible mechanisms may prevail [17].

In the first mechanistic pathway, known as the hydrogen atom transfer (HAT) and summarized in equation 1 , an $\mathrm{ArO}-\mathrm{H}$ antioxidant donates its $\mathrm{H}$ atom to a hot free radical $\mathrm{R}^{\bullet}$, which is converted into a neutral species $\mathrm{RH}$ alongside a less reactive ArO radical [37]-PT. In the framework of the HAT mechanism, the antioxidant activity is readily assessed by computing the Bond Dissociation Enthalpy (BDEs) of the $\mathrm{O}-\mathrm{H}$ bonds of the antioxidant. Since BDEs measure the amount of energy required to break a bond in a homolytic fashion, small BDEs are to be associated with higher antioxidant activity [15].

$\mathrm{R}^{\bullet}+\mathrm{ArOH} \rightarrow \mathrm{RH}+\mathrm{ArO}^{*}$

Equation 2 illustrates the second mechanism, i.e. the stepwise electron transfer proton transfer (SET-PT) route. On this path, an ArO-H molecule consecutively withdraws one electron and a proton onto the free radical, leading to the same products as in the HAT route [38]. The ionization potential (IP) and proton dissociation enthalpy (PDE) of the antioxidant are the most 
used indicators of the antioxidant activity in this context, low IPs and PDEs being associated with great antioxidant properties [39].

$\mathrm{R}^{\bullet}+\mathrm{ArOH} \rightarrow \mathrm{R}^{-}+\mathrm{ArO}^{++} \rightarrow \mathrm{RH}+\mathrm{ArO}^{\circ}$

The third mechanistic pathway (equations 3-5) has been named sequential proton loss electron transfer (SPLET) as it involves the heterolytic dissociation of $\mathrm{O}-\mathrm{H}$ bond before the subsequent shift of a single electron from $\mathrm{ArO}^{-}$to the free radical [40]. In so far as this mechanism is concerned, the proton affinity (PA) and electron transfer enthalpy (ETE) are the most suitable thermodynamics parameter to discuss the activity of antioxidants. It is widely admitted that the lower the PAs and ETEs are, the higher the antioxidant activity [41].

$$
\begin{aligned}
& \mathrm{ArOH} \rightarrow \mathrm{ArO}^{-}+\mathrm{H}^{+} \\
& \mathrm{ArO}^{-}+\mathrm{R}^{\cdot} \rightarrow \mathrm{ArO}^{-}+\mathrm{R}^{-} \\
& \mathrm{R}^{-}+\mathrm{H}^{+} \rightarrow \mathrm{RH}
\end{aligned}
$$

\subsection{Computational details}

Following each of the three mechanisms of free radical scavenging, we investigate here the antioxidant activity of GA, PHBA, PCA, SA, and VA in vacuum (gas phase) and solution (water and methanol) using the Gaussian 09 software [42]. All the structures, i.e. parent molecules, radicals, cations, and anions, were fully optimized using the meta hybrid M06-2X functional in conjunction with the $6-311++G(d, p)$ basis set. Note that the M06-2X/6-311++G(d,p) level of theory has been successfully applied in numerous previous studies on antioxidant activities and was found to provide reliable results [35][43]. All the structures returned upon optimization were confirmed by vibrational frequency calculations to be real minima on the potential energy surface. Moreover, Noncovalent Index $(\mathrm{NCl})$ calculations were performed to probe intramolecular noncovalent contacts in the gas phase structure of the antioxidants. 
Considering a typical antioxidant noted $\mathrm{ArOH}$, equations 6-10 are used to calculate BDE, IP, PA, PDE, and ETE values. In the gas phase, formation enthalpies of $1.483 \mathrm{kcal} / \mathrm{mol}$ and 0.752 $\mathrm{kcal} / \mathrm{mol}$ were used for the proton and electron respectively as obtained by Bartmess through numerical solution of Fermi-Dirac statistical mechanics equations [29]. Solvation enthalpies of the proton and electron in water and methanol were retrieved from a benchmarking study by Rimarčík and coworkers [44]. Solvent contributions to the total enthalpies were accounted for using the integral equation formalism IEF-PCM method [45][46] as implemented in the Gaussian 09 software with default settings at $298.15 \mathrm{~K}$ and 1 atmosphere. Note that the IEF-PCM solvation model is not only computationally affordable, but also known to provide acceptably accurate results [47].

$$
\begin{aligned}
& \mathrm{BDE}=\mathrm{H}\left(\mathrm{ArO}^{\circ}\right)+\mathrm{H}\left(\mathrm{H}^{\circ}\right)-\mathrm{H}(\mathrm{ArOH}) \\
& \mathrm{IP}=\mathrm{H}\left(\mathrm{ArO}^{+}\right)+\mathrm{H}\left(\mathrm{e}^{-}\right)-\mathrm{H}(\mathrm{ArOH}) \\
& \mathrm{PDE}=\mathrm{H}\left(\mathrm{ArO}^{\circ}\right)+\mathrm{H}\left(\mathrm{H}^{+}\right)-\mathrm{H}\left(\mathrm{ArOH}^{+\bullet}\right) \\
& \mathrm{PA}=\mathrm{H}\left(\mathrm{ArO}^{-}\right)+\mathrm{H}\left(\mathrm{H}^{+}\right)-\mathrm{H}\left(\mathrm{ArOH}^{\circ}\right) \\
& E T E=\mathrm{H}\left(\mathrm{ArO}^{\circ}\right)+\mathrm{H}\left(\mathrm{e}^{-}\right)-\mathrm{H}\left(\mathrm{ArO}^{-}\right)
\end{aligned}
$$

To understand the local and global reactivity of the five benzoic acid derivatives, their frontier molecular orbitals were computed at the M06-2X/6-311+G(d,p) level and examined. The visualization was performed using Chemcraft [48] and VMD [49]. 


\section{Results and Discussion}

\subsection{Optimized geometries}

Parent molecules were fully optimized at the M06-2X/6-311++G(d, p) level in the gas, $\mathrm{H}_{2} \mathrm{O}$ and $\mathrm{MetOH}$ phases. Figure 1 presents their structures as well as the atomic numbering and convention used herein to differentiate the $-\mathrm{OH}$ groups of each molecule. Owing to the distinct electronic surroundings of $\mathrm{OH}$ groups as shown in Figure 1, one should expect them to exhibit different reactivity towards free radicals. It is almost universally admitted that the greatest reactivity of benzoic acid derivatives is held in the $-\mathrm{OH}$ group in para position of the carboxylic group holds [50]. In the present study, this observation is discussed in the context of all the three mechanisms.

Table $\mathrm{S} 1$ collects $\mathrm{O}-\mathrm{H}$ and $\mathrm{C}=\mathrm{O}$ bond lengths in all the parent molecules obtained at the M06-2X/6-311++G(d, p) level. It is immediately clear from this table that the carboxylic OH group 1 is slightly longer than the others and measures on average 0.967 in the gas phase and $0.968 \AA$ in both water and methanol solutions. Moreover, the length of $\mathrm{C}=\mathrm{O}$ bonds is estimated to roughly $1.202 \AA$ in vacuum, and $1.208 \AA$ in both $\mathrm{H}_{2} \mathrm{O}$ and $\mathrm{MetOH}$. These values suggest that both the $\mathrm{O}-\mathrm{H}$ and $\mathrm{C}=\mathrm{O}$ are weakly stretched in polar environments, with elongations reaching up to $0.003 \AA$ and $0.006 \AA ̊$ respectively.

In order to probe intramolecular noncovalent interactions in the neutral structure of the five antioxidants, $\mathrm{NCl}$ calculations were carried out in gas phase for all the compounds. The $\mathrm{NCI}$ plots obtained at the 0.05 isosurface are given in Figure 2. 

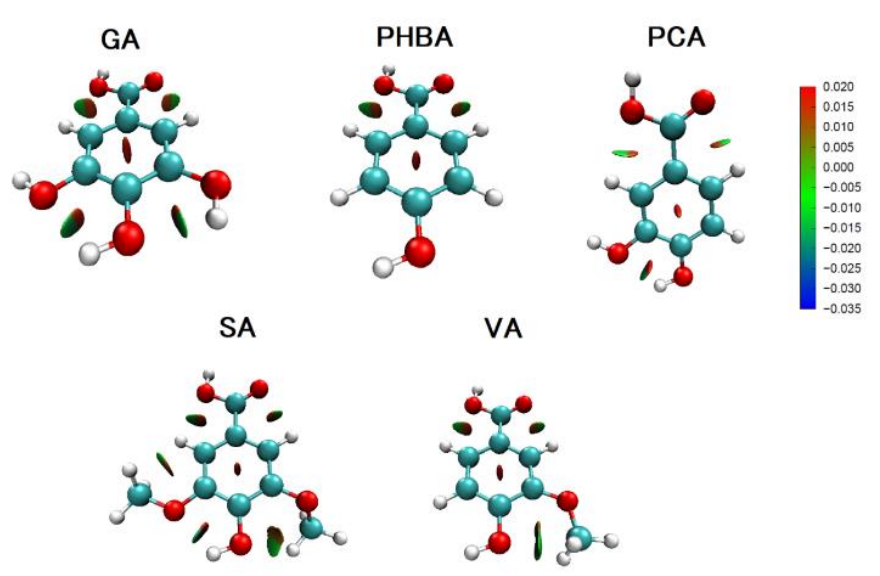

VA

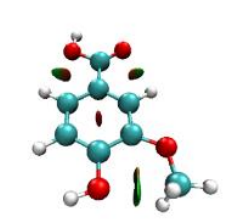

Figure 2. $\mathrm{NCl}$ isosurfaces obtained using the $\mathrm{M} 06-2 \mathrm{X} / 6-11++\mathrm{G}(\mathrm{d}, \mathrm{p})$ electron density and reduced density gradient.

Figure 2 not only confirms the presence of intramolecular noncovalent interactions in the structure of all the five molecules, but also reveals that the two $O$ atoms of the carboxylic groups are engaged in non-classical $\mathrm{O} \ldots \mathrm{H}-\mathrm{C}$ hydrogen bonding interactions with the $\mathrm{H}$ atoms at ortho position. In line with the common interpretation of $\mathrm{NCI}$ plots [51], the greenish color of the elliptical slabs indicate that these intramolecular contacts are weak attractive interactions.

\subsection{HAT mechanism}

In the HAT mechanism of antioxidant activity, an $\mathrm{H}$ atom is directly transferred to the free radical by homolytic cleavage of the $\mathrm{O}-\mathrm{H}$ bond [5]. The bond dissociation enthalpy (BDE) is the most used thermodynamics parameter to appraise the ease with which this breakage occurs. Low BDEs values are then related to high antioxidant power. Table 1 collects calculated BDEs of the five antioxidants in gas, $\mathrm{H}_{2} \mathrm{O}$, and $\mathrm{MetOH}$ phases.

At first glance, this table reveals that BDEs span over a $33.7 \mathrm{kcal} / \mathrm{mol}$ range of values going from 78.2 to $111.9 \mathrm{kcal} / \mathrm{mol}$. This range is in good agreement with other theoretical works on other systems [52][53] and gives more credit to the data reported here. In the gas phase, the lowest $\mathrm{BDE}$ is associated with the $\mathrm{OH}$ group 3 of PCA, while the highest corresponds to the 
carboxylic $\mathrm{OH}$ group 1 of VA. Based on lowest BDEs values, one can advance the following order of antioxidant activity in the gas phase: $\mathrm{PHBA}<\mathrm{SA}<\mathrm{VA}<\mathrm{GA}<\mathrm{PCA}$. In addition, it is worth noting that the $\mathrm{OH}$ group in para position exhibits the lowest BDEs in all the compounds and should therefore be the most active in the gas phase through the HAT pathway.

Turning now on the results in solution, Table 1 reveals some interesting insights. Looking first at the raw BDE differences between the gas phase and solution, one should notice that the hydrogen abstraction ability of these compounds is only slightly affected by the two polar solvents. Indeed, BDEs deviations between the gas phase and solution are lower than $6,11,6,7$ and 8 $\mathrm{kcal} / \mathrm{mol}$ for GA, PHBA, PCA, SA and VA respectively. These fluctuations evaluate to less than $10 \%$ of the dissociation enthalpy in the gas phase, and agree well with previous findings of the antioxidant activity of benzoic acid derivatives [35]. Moreover, GA appears to be the most active in $\mathrm{H}_{2} \mathrm{O}$ and $\mathrm{MetOH}$ solutions, with the lowest $\mathrm{BDE}$ of 78.2 and $80.4 \mathrm{kcal} / \mathrm{mol}$ respectively in water and methanol attributed to the $\mathrm{OH}$ group 3. These values have the same ballpark as the BDEs of GA obtained experimentally by Denisova et al [54], and Alberti et al [55], who found 83.03 and $81.00 \mathrm{kcal} / \mathrm{mol}$ in methyl linoleate and acetonitrile/chlorobenzene respectively. Further, the trend of antioxidant activity in solution is slightly different as GA gets more active than PCA [PHBA < $\mathrm{SA}<\mathrm{VA}<\mathrm{PCA}<\mathrm{GA}]$ 
Table 1. Bond dissociation enthalpies (BDE in $\mathrm{kcal} / \mathrm{mol}$ ) of the investigated benzoic acid derivatives in vacuum and solution (water and methanol) were computed at M06-2X/6-311++G(d, p) level.

\begin{tabular}{|c|c|c|c|c|c|}
\hline Antioxidant & Medium & O-H(1) & O-H(2) & O-H(3) & O-H(4) \\
\hline \multirow{3}{*}{ GA } & gas & 110.8 & 80.2 & 80.3 & 88.0 \\
\hline & water & 105.1 & 80.7 & 78.2 & 83.8 \\
\hline & methanol & 107.9 & 82.8 & 80.4 & 86.1 \\
\hline \multirow{3}{*}{ PHBA } & gas & 110.6 & 88.1 & & \\
\hline & water & 110.8 & 87.8 & & \\
\hline & methanol & 121.4 & 89.9 & & \\
\hline \multirow{3}{*}{ PCA } & gas & 110.8 & 87.4 & 78.8 & \\
\hline & water & 105.1 & 83.7 & 79.4 & \\
\hline & methanol & 107.8 & 86.0 & 81.5 & \\
\hline \multirow{3}{*}{ SA } & gas & 110.5 & 83.5 & & \\
\hline & water & 104.1 & 84.4 & & \\
\hline & methanol & 106.8 & 86.4 & & \\
\hline \multirow{3}{*}{ VA } & gas & 111.9 & 80.7 & & \\
\hline & water & 104.6 & - & & \\
\hline & methanol & 109.2 & 85.7 & & \\
\hline
\end{tabular}

The BDEs values reported in Table 1 enable to identify the most active site and compound in gas and polar media in the context of the HAT mechanism. However, they do not indicate why this should be so. After homolytic breakage of an $\mathrm{O}-\mathrm{H}$ bond, the single electron left on the $\mathrm{O}$ atom delocalizes over the molecule and one can assume that the more it spreads away from its initial position, the higher the stability of the radical and the lower should be the BDE. Therefore, the difference in BDE values may be explained based on the distribution of spin densities [56].

In order to comprehend the origin of the different BDEs of $\mathrm{O}-\mathrm{H}$ bonds in gas phase, spin density distributions of the radicals were calculated at the $M 06-2 X / 6-311++G(d, p)$ level and are here listed in Table 2. Inspection of this table asserts that for the same compound, the $\mathrm{OH}$ group in para position has the lowest spin density estimated to $0.66,0.67 .0 .68 .0 .71$ and 0.61 respectively for GA, PHBA, PCA, SA and VA, and should lead to the most stable radical. This 
observation is consistent with the BDEs listed in Table 1, which showed these $\mathrm{OH}$ groups to be the most active. Similarly, the highest spin density of $0.96-0.98$ predicted for the carboxylic $\mathrm{OH}$ group corroborate well with the high BDEs reported in Table 1.

Table 2. Local spin density calculated on the $\mathrm{O}$ atom after the homolytic cleavage of $\mathrm{O}-\mathrm{H}$ bond in the gas, $\mathrm{H}_{2} \mathrm{O}$ and MetOH phases. Values calculated at the $\mathrm{M} 06-2 \mathrm{X} / 6-311++\mathrm{G}(\mathrm{d}, \mathrm{p})$ level.

\begin{tabular}{lllll}
\hline Antioxidant & $\mathbf{O}(\mathbf{1})$ & $\mathbf{O}(2)$ & $\mathbf{O}(3)$ & $\mathbf{O}(4)$ \\
\hline GA & 0.97 & 0.70 & 0.66 & 0.68 \\
PHBA & 0.97 & 0.67 & & \\
PCA & 0.96 & 0.70 & 0.68 & \\
SA & 0.98 & 0.71 & & \\
VA & 0.97 & 0.61 & & \\
\hline
\end{tabular}

However, it must be emphasized that this analysis relying on local spin densities only holds when it comes to identifying the most active site within the same compound, but does not account for the order of lowest BDEs throughout the whole dataset of five compounds. For example, the spin density on the $\mathrm{OH}$ group 2 of $\mathrm{VA}(0.61)$ is lower than that of the $\mathrm{OH}$ group 3 of PCA (0.68), while the BDE of the former is $1.9 \mathrm{kcal} / \mathrm{mol}$ greater than that of the latter. This finding is consistent with the results reported by Wang et al on a series of 2,3,4-trimethoxy chalcones [57].

\subsection{SET-PT mechanism}

In terms of SET-PT mechanism, ionization potentials (IPs) and proton dissociation enthalpies (PDEs) serve to investigate the antioxidant power. A rule of thumb is that, the lower the IPs and PDEs, the greater the antioxidant activity. Table 3 reports the calculated IPs and PDEs of the five antioxidants in the gas phase and $\mathrm{H}_{2} \mathrm{O}$ and MetOH solutions at the M06-2X/6$311++G(d, p)$ level.

Results in Table 3 reveal that the IP values of the five antioxidants range between 185.5 and $195.5 \mathrm{kcal} / \mathrm{mol}$ in gas phase, and between 121.8 and $132.9 \mathrm{kcal} / \mathrm{mol}$, and 127.1 and 138.3 
$\mathrm{kcal} / \mathrm{mol}$ respectively in water and methanol. These values are in the same range as those obtained in previous studies [58][59]. Noteworthy is that IPs values suggest either of the following orders of antioxidant activity which are far different from the one obtained with BDEs: PHBA < $\mathrm{PCA} \mathrm{GA}<\mathrm{VA}<\mathrm{SA}, \mathrm{PHBA}<\mathrm{GA} \sim \mathrm{PCA}<\mathrm{VA}<\mathrm{SA}$ and $\mathrm{PHBA}<\mathrm{VA}<\mathrm{GA} \sim \mathrm{PCA}<\mathrm{SA}$ in gas phase, $\mathrm{H}_{2} \mathrm{O}$ and methanol respectively. This apparent discrepancy between IPs and BDEs induced patterns is not surprising. It resorts to the fact BDEs are local quantities depending on the relative positions of substituents, whereas IPs are global parameters affected by the structure of the entire molecule [60].

Table 3. Ionization potential (IP) and proton dissociation enthalpy (PDE) computed at the M06$2 X / 6-311++G(d, p)$ level. PDE values are provided for each site. Values are given in $\mathrm{kcal} / \mathrm{mol}$.

\begin{tabular}{|c|c|c|c|c|c|c|}
\hline \multirow[t]{2}{*}{ Antioxidant } & \multirow[t]{2}{*}{ Medium } & \multirow[t]{2}{*}{ IP } & \multicolumn{4}{|c|}{ PDE } \\
\hline & & & O1-H & O2-H & O3-H & O4-H \\
\hline \multirow{3}{*}{ GA } & vacuum & 194.4 & 232. 3 & 201.6 & 201.8 & 209.5 \\
\hline & water & 124.8 & 27.9 & 3.6 & 1.0 & 6.5 \\
\hline & methanol & 130.1 & 23.9 & -1.2 & -3.6 & 2.0 \\
\hline \multirow{3}{*}{ PHBA } & vacuum & 204.2 & 222.3 & 199.8 & & \\
\hline & water & 132.9 & 2.4 & 2.4 & & \\
\hline & methanol & 138.3 & 29.3 & -2.3 & & \\
\hline \multirow{3}{*}{ PCA } & vacuum & 195.2 & 231.5 & 208.1 & 199.5 & \\
\hline & water & 124.6 & 28.0 & 6.7 & 2.4 & \\
\hline & methanol & 129.9 & 24.0 & 2.1 & -2.3 & \\
\hline \multirow{3}{*}{ SA } & vacuum & 185.5 & 240.9 & 213.9 & & \\
\hline & water & 121.8 & 29.7 & 10.4 & & \\
\hline & methanol & 127.1 & 25.8 & 5.5 & & \\
\hline \multirow{3}{*}{ VA } & vacuum & 189.6 & 238.2 & 207.1 & & \\
\hline & water & 122.5 & 29.7 & 7.0 & & \\
\hline & methanol & 134.1 & 19.2 & -4.2 & & \\
\hline
\end{tabular}

It is worth noting that IPs decrease drastically from the gas phase to polar media. For instance, the IP of SA plummets from 185.5 to $124.6 \mathrm{kcal} / \mathrm{mol}$ on going from the gas phase to 
aqueous solution. This indicates that polar solvents considerably facilitate the electron transfer to the free radicals and thus enhance the antioxidant activity. This result is in agreement with many documented studies on antioxidant properties [61]. Furthermore, IP values follow the order water $<$ methanol < gas, which indicate that the stronger the solvent polarity, the higher the electrondonating ability of the molecule [62].

The proton dissociation enthalpy (PDE) characterizes the second step of the SET-PT mechanism and indicates the thermodynamically preferred $\mathrm{OH}$ group for deprotonation from the cation radical. It can be seen from Table 3 that the lowest PDE in all the three environments is associated to the $\mathrm{OH}$ group in para position, and agrees well with the results based on BDEs. Moreover, PCA has the lowest PDE in gas phase, while this applies to GA in polar solution. Like IP values, there are substantial decrease of PDEs in solution as compared to the gas phase, which may be ascribed to the high stabilization of the positively charged proton in polar solution. Note that, in gas phase, the lowest PDEs suggest the following order of antioxidant activity SA < $\mathrm{VA}<\mathrm{GA}<\mathrm{PHBA}<\mathrm{PCA}$, which is slightly different from the one obtained in solution, namely SA $<\mathrm{VA}<\mathrm{PHBA}<\mathrm{PCA}<\mathrm{GA}$. The negative $\mathrm{PDE}$ values predicted for some $\mathrm{OH}$ groups may suggest a plausible mediation of the solvent in the heterolytic breakage of the $\mathrm{O}-\mathrm{H}$ bonds of the radical cation, pulling and favoring the ejection of the proton with no need for extra energy. Wang et al reported similar data in their investigation of the antioxidant activity of genistein and its nitro and amino derivatives [57].

\subsection{SPLET mechanism}

Table 4 presents proton affinities (PAs) and electron transfer enthalpies (ETEs) of GA, PHBA, PCA, SA and VA in the gas phase and polar $\left(\mathrm{H}_{2} \mathrm{O}\right.$ and $\left.\mathrm{MetOH}\right)$ solutions at the M06-2X/6$311++G(d, p)$ level. In gas phase, PA values are comprised between 329.2 and $344.0 \mathrm{kcal} / \mathrm{mol}$, the lowest and highest values being associated with the $\mathrm{O} 2-\mathrm{H}$ and $\mathrm{O} 4-\mathrm{H}$ groups of $\mathrm{GA}$. It must be 
noted that, in gas phase, the $\mathrm{O} 2-\mathrm{H}$ bond has the lowest PA and should be the most likely to undergo a heterolytic breakage; in polar solution, this is true for the $\mathrm{O} 1-\mathrm{H}$ bond except for $\mathrm{GA}$ in water where $\mathrm{O} 4-\mathrm{H}$ has the lowest PA of $30.5 \mathrm{kcal} / \mathrm{mol}$. Inspection of Table 4 reveals that PAs drop considerably when going from gas phase to polar solution ( where PA values are lower than $39.1 \mathrm{kcal} / \mathrm{mol}$ ), following the order gas phase $<<$ water $<$ methanol. This pattern can be related to the high stability of the radical anion and proton in solution as compared to the gas phase. Considering the lowest PA values in gas phase, one can deduce the following order of antioxidant activity $\mathrm{PHBA} \sim \mathrm{SA}<\mathrm{VA}<\mathrm{PCA}<\mathrm{GA}$ in gas phase, which changes to $\mathrm{PHBA} \sim \mathrm{VA}<\mathrm{PCA}<\mathrm{SA}<\mathrm{GA}$ in polar medium.

The second step of the SPLET mechanism corresponds to the fixation of an electron from the free radicals. The capability to trap that electron is estimated by the electron transfer enthalpy defined in equation 10. ETE values listed in Table 4 are in between 58.0 and $89.4 \mathrm{kcal} / \mathrm{mol}$ in gas phase and 91.1 and $136.8 \mathrm{kcal} / \mathrm{mol}$ in polar solution. In gas phase, site O2 has the lowest ETE value, except in the case of GA for which it is site $\mathrm{O} 4$ instead. As such, one can expect these sites (O2 and $\mathrm{O} 4$ for $\mathrm{GA}$ ) to be enriched in extra electron density by a striking free radical. Moreover, looking at the lowest ETE values in gas phase, VA appears to be the ablest to trap an electron from a free radical, followed respectively by GA, PCA, SA and PHBA.

In contrast with PAs, ETE values increase in solution, even if their rise is less pronounced as compared to the decrease of PA values. This finding can be explained by the high solubility of the radical anion ( $\left.\mathrm{ArO}^{-}\right)$in solution. Note that site $\mathrm{O} 2$ has the lowest ETE in both solvents for all compounds except GA, for which site $\mathrm{O} 3$ and $\mathrm{O} 4$ come up with the lowest ETE values of 91.1 and $93.6 \mathrm{kcal} / \mathrm{mol}$ respectively in water and methanol respectively. In line with the lowest ETE values, the electron transfer ability of these compounds is as follows: PHBA $<$ SA $<\mathrm{PCA}<\mathrm{VA}$ GA in both water and methanol, and is very close to that observed in gas phase. 
Table 4. Proton affinity (PA) and electron transfer enthalpy (ETE) computed at the M06-2X/6$311++\mathrm{G}(\mathrm{d}, \mathrm{p})$ level. ETE values are provided for each site. Values are given in $\mathrm{kcal} / \mathrm{mol}$.

\begin{tabular}{|c|c|c|c|c|c|c|c|c|c|}
\hline \multirow[t]{2}{*}{ Antioxidant } & \multirow[t]{2}{*}{ Medium } & \multicolumn{4}{|c|}{ PA } & \multicolumn{4}{|c|}{ ETE } \\
\hline & & O1-H & $\mathrm{O} 2-\mathrm{H}$ & $\mathrm{O} 3-\mathrm{H}$ & O4-H & O1-H & $\mathrm{O} 2-\mathrm{H}$ & $\begin{array}{c}\text { O3- } \\
\mathbf{H}\end{array}$ & $\begin{array}{c}\text { O4- } \\
\text { H }\end{array}$ \\
\hline \multirow{3}{*}{ GA } & vacuum & 337.3 & 329.2 & 330.3 & 344.0 & 89.4 & 67.0 & 65.9 & 59.9 \\
\hline & water & 39.1 & 31.8 & 33.2 & 30.5 & 112.0 & 95.0 & 91.1 & 99.4 \\
\hline & methanol & 29.3 & 31.7 & 30.4 & 37.9 & 124.1 & 96.7 & 95.5 & 93.6 \\
\hline \multirow{3}{*}{ PHBA } & vacuum & 339.3 & 332.5 & & & 87.2 & 71.5 & & \\
\hline & water & 31.3 & 34.4 & & & 125.5 & 99.4 & & \\
\hline & methanol & 30.2 & 32.9 & & & 136.8 & 102.5 & & \\
\hline \multirow{3}{*}{ PCA } & vacuum & 337.5 & 330.5 & 337.0 & & 89.2 & 64.3 & 66.3 & \\
\hline & water & 30.9 & 33.4 & 35.9 & & 120.2 & 92.0 & 93.8 & \\
\hline & methanol & 29.7 & 31.9 & 34.6 & & 123.6 & 95.1 & 96.9 & \\
\hline \multirow{3}{*}{ SA } & vacuum & 337.7 & 332.3 & & & 88.7 & 67.8 & & \\
\hline & water & 30.6 & 35.9 & & & 119.5 & 94.5 & & \\
\hline & methanol & 29.4 & 34.5 & & & 122.9 & 97.4 & & \\
\hline \multirow{3}{*}{ VA } & vacuum & 338.6 & 331.8 & & & 89.1 & 58.0 & & \\
\hline & water & 31.0 & 36.4 & & & 119.7 & 91.6 & & \\
\hline & methanol & 30.1 & 35.2 & & & 123.2 & 94.7 & & \\
\hline
\end{tabular}




\subsection{Thermodynamically preferred mechanism}

As stated above, IP and PA values characterize the first step of the SET-PT and SPLET mechanisms, while BDEs describe the unique reaction of the HAT mechanism. Having this in mind, previous studies have attempted to determine the thermodynamically preferred reaction pathway of several families of antioxidants by comparing the relative magnitude of BDEs, IPs and PAs [43][63]. The same approach is here applied.

As far as the present study is concerned, BDEs are substantially smaller than IPs and PAs in gas phase. This suggests that the antioxidant activity of GA, PHBA, PCA, SA and VA can be considered as driven by the HAT mechanism in gas phase and corroborates with Urbaniak et al[64]. Therefore, PCA and PHBA should display respectively the highest and lowest antioxidant activity in gas phase. Furthermore, Tables 1, 3-4 reveal that, in polar solution, PAs are very low as compared to BDEs and IPs. This finding indicates that the SPLET mechanism should be the most favorable in water and methanol. As such, GA and PHBA should be the most and least active in polar medium. Note that, regardless of the environment, PHBA seems to be the least active of the set.

\subsection{Frontier molecular orbitals}

Frontier molecular orbitals (FMOs) are widely used to probe the reactivity of molecular systems [65]. Most often, one can rely on the electronic density distribution in these orbitals to predict the most preferred attack site for free radicals and other reactive agents [63]. More interestingly, previous studies have shown that the free radical scavenging ability of phenolic compounds can be related to the energy of the HOMO such that molecules with higher HOMO energies are likely to be more active due to the stronger electron donating ability [43][63]. To check this "HOMO-rule" and assess the local reactivity of the compounds considered here, FMOs 
of the five antioxidants were computed in the three environments. Figure 3 displays the electron density distribution of the FMOs of our antioxidants in gas phase (qualitatively equivalent plots were obtained in solution), as well as the corresponding energies. Electronic energies associated with the $\mathrm{HOMO}$ and LUMO in gas phase and $\mathrm{H}_{2} \mathrm{O}$ and MetOH solutions are provided in Table 5.

Figure 3 shows that the electron densities of the HOMO and LUMO are delocalized over a big portion of these molecules. The concentration of this density on $\mathrm{O}$ atoms and $\mathrm{C}$ atoms of the benzene ring suggests these atoms to be the preferred attack site for free radicals [57]. However, the reactions on $\mathrm{C}$ sites has not been considered and may constitute the core of a separate study.

It can be seen from Table 5 that polar solvents stabilize FMOs of the five antioxidant, their effect being more pronounced on the LUMO than the HOMO. Furthermore, note that VA and PHBA are predicted as having the strongest and weakest electron donating abilities in gas phase, with $\mathrm{HOMO}$ energies of -7.60 and $-8.17 \mathrm{eV}$ respectively, whereas in polar medium, SA has the highest HOMO energy valued at $7.81 \mathrm{eV}$ and should possess the greatest free radical scavenging power as far as the HOMO rule is assumed correct.

However, looking at the HOMO energies collected in Table 5, one may infer the following orders of free scavenging ability: $\mathrm{PHBA}<\mathrm{GA} \sim \mathrm{PCA}<\mathrm{SA}<\mathrm{VA}$ and $\mathrm{PHBA}<\mathrm{VA}<\mathrm{GA}<\mathrm{PCA}<$ SA in gas and polar phases respectively, which do not seem to corroborate with any of the patterns predicted considering either of BDEs, IPs, PDEs, PAs and ETEs. This finding may indicate that the HOMO rule is not absolute, and may be misleading in the discussion of the antioxidant activity. An argument upholding this assumption is that, although the "HOMO-rule" was found to reproduce IPs patterns in the case of quercetin and analogues [43], it does not work for the current benzoic acid derivatives. 
GA

PHBA

PCA

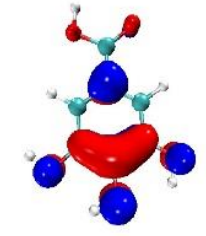

номо $(-7.86 \mathrm{eV})$

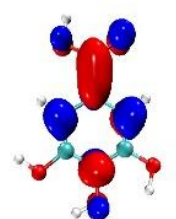

LUMO $(-0.55 \mathrm{eV})$

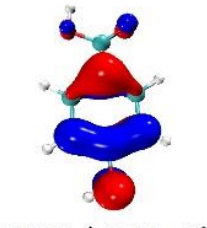

HOMO (-8.17 eV)

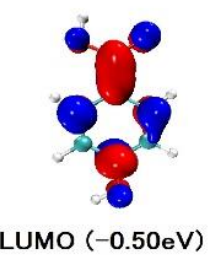

SA

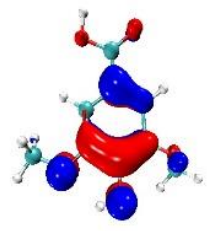

HOMO $(-7.72 \mathrm{eV})$

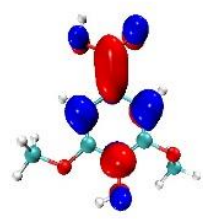

LUMO $(-0.50 \mathrm{eV})$

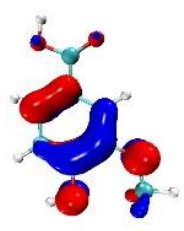

HOMO (-7.60 eV)

VA

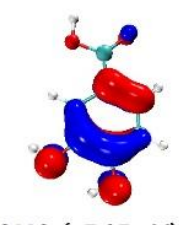

номо (-7.85 eV)

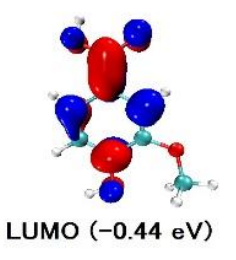

Figure 3. Frontier molecular orbitals of GA, PHBA, PCA, SA and VA in gas phase at the M062X/6-311++G(d,p) level.

Table 5. Frontier molecular orbitals (FMOs) energies computed in gas phase and polar $\left(\mathrm{H}_{2} \mathrm{O}\right.$ and $\mathrm{MetOH}$ ) solution at the M06-2X/6-311++G(d,p) level. Values are expressed in eV.

\begin{tabular}{lllll}
\hline Antioxidant & FMO & Gas & Water & Methanol \\
\hline \multirow{2}{*}{ GA } & HOMO & -7.86 & -7.89 & -7.89 \\
& LUMO & -0.55 & -0.67 & -0.67 \\
PHBA & HOMO & -8.17 & -8.19 & -8.19 \\
& LUMO & -0.50 & -0.62 & -0.61 \\
PCA & HOMO & -7.85 & -7.87 & -7.87 \\
& LUMO & -0.56 & -0.66 & -0.65 \\
SA & HOMO & -7.72 & -7.81 & -7.81 \\
& LUMO & -0.50 & -0.69 & -0.68 \\
VA & HOMO & -7.60 & -8.11 & -8.10 \\
& LUMO & -0.44 & -0.68 & -0.67 \\
\hline
\end{tabular}




\section{Concluding remarks}

The antioxidant activity of five benzoic acid derivatives has been investigated at the M06$2 X / 6-311++G(d, p)$ level, following three possible mechanisms of antioxidant activity in gas and polar phases. Our findings suggest that the hydrogen atom transfer (HAT) is the preferred mechanistic pathway in gas phase, while the sequential proton loss electron transfer (SPLET) is favored in polar mediums. Protocatechuic and gallic acids (PCA and GA) are the most active in gas and polar solutions respectively, whereas PHBA is the least active in all the environments considered. Solvents are found to induce considerable changes in the enthalpies of charged species, explaining some drastic variations in proton affinities (PA) and Proton Dissociation Enthalpies (PDE) when going from gas phase to polar solutions. The O-H group in para position of the carboxylic group (O3-H for $\mathrm{GA}$ and $\mathrm{O} 2-\mathrm{H}$ for the rest) is the most reactive site in gas phase, while in solution it is either the $\mathrm{O} 1-\mathrm{H}$ site for PHBA, PCA, SA and VA, or O4-H for GA.

\section{Acknowledgements}

Bienfait K. Isamura is grateful to Prof Kevin Lobb at Rhodes University and the Center for High Performance Computing (CHPC) for having provided the resources used to carry out this study (project CHEM0802).

\section{References}

[1] M.G. Traber, J. Atkinson, Vitamin E, antioxidant and nothing more, Free Radic. Biol. Med. 43 (2007) 4-15. https://doi.org/10.1016/j.freeradbiomed.2007.03.024.

[2] T. Akaike, M. Suga, H. Maeda, Free Radicals in Viral Pathogenesis :, Mol. Biol. Med. 217 (1998) 64-73. https://doi.org/10.3181/00379727-217-44206.

[3] G. Buonocore, S. Perrone, M.L. Tataranno, Oxygen toxicity: Chemistry and biology of reactive oxygen species, Semin. Fetal Neonatal Med. 15 (2010) 186-190. 
https://doi.org/10.1016/j.siny.2010.04.003.

[4] A. Phaniendra, D.B. Jestadi, L. Periyasamy, Free Radicals: Properties, Sources, Targets, and Their Implication in Various Diseases, Indian J. Clin. Biochem. 30 (2015) 11-26. https://doi.org/10.1007/s12291-014-0446-0.

[5] E.M. Heider, J.K. Harper, D.M. Grant, A. Hoffman, F. Dugan, D.P. Tomer, K.L. O'Neill, Exploring unusual antioxidant activity in a benzoic acid derivative: A proposed mechanism for citrinin, Tetrahedron. 62 (2006) 1199-1208. https://doi.org/10.1016/j.tet.2005.10.066.

[6] J. Du, J.M. Gebicki, Proteins are major initial cell targets of hydroxyl free radicals, Int. J. Biochem. Cell Biol. 36 (2004) 2334-2343. https://doi.org/10.1016/j.biocel.2004.05.012.

[7] C. Chatgilialoglu, P. O'Neill, Free radicals associated with DNA damage, Exp. Gerontol. 36 (2001) 1459-1471. https://doi.org/10.1016/S0531-5565(01)00132-2.

[8] I.K. Elaka, P.M. Kapepula, N.K. Ngombe, J.M. Mpoyi, D.M. Lukusa, M.M. Muabilwa, C.K. Gabha'Bey, C.M. Lukukula, B.N. Lukebakio, M.K. Okuna, D.M. Kialengila, P.T. Kantola, Microscopic Features, Antioxidant and Antibacterial Capacities of Plants of the Congolese Cosmetopoeia, Raw Materials of Cosmeceuticals, J. Biosci. Med. 08 (2020) 149-166. https://doi.org/10.4236/jbm.2020.89013.

[9] O. Arrigoni, M.C. De Tullio, Ascorbic acid: Much more than just an antioxidant, Biochim. Biophys. Acta - Gen. Subj. 1569 (2002) 1-9. https://doi.org/10.1016/S03044165(01)00235-5.

[10] M. Butnariu, I. Samfira, Free Radicals and Oxidative Stress, J. Bioequiv. Availab. 04 (2012). https://doi.org/10.4172/jbb.10000e13. 
[11] C. Peña-Bautista, M. Baquero, M. Vento, C. Cháfer-Pericás, Free radicals in Alzheimer's disease: Lipid peroxidation biomarkers, Clin. Chim. Acta. 491 (2019) 85-90. https://doi.org/10.1016/j.cca.2019.01.021.

[12] D. Dreher, A.F. Junod, Role of Oxygen Free Radicals in Cancer Development, Eur. J. Cancer. 32 (1996) 30-38. https://doi.org/10.1016/0959-8049(95)00531-5.

[13] M. Parola, G. Robino, Oxidative stress-related molecules and liver fibrosis, J. Hepatol. 35 (2001) 297-306. https://doi.org/10.1016/S0168-8278(01)00142-8.

[14] S.A.B.E. Van Acker, D.J. Van Den Berg, M.N.J.L. Tromp, D.H. Griffioen, W.P. Van Bennekom, W.J.F. Van Der Vijgh, A. Bast, Structural aspects of antioxidant activity of flavonoids, Free Radic. Biol. Med. 20 (1996) 331-342. https://doi.org/10.1016/08915849(95)02047-0.

[15] S. Llano, S. Gómez, J. Londoño, A. Restrepo, Antioxidant activity of curcuminoids, Phys. Chem. Chem. Phys. 21 (2019) 3752-3760. https://doi.org/10.1039/c8cp06708b.

[16] M.P. Kähkönen, M. Heinonen, Antioxidant activity of anthocyanins and their aglycons, J. Agric. Food Chem. 51 (2003) 628-633. https://doi.org/10.1021/jf025551i.

[17] A.C. Kurilich, J.A. Juvik, Quantification of carotenoid and tocopherol antioxidants in Zea mays, J. Agric. Food Chem. 47 (1999) 1948-1955. https://doi.org/10.1021/jf981029d.

[18] N.I. Krinsky, Carotenoids as antioxidants, Nutrition. 17 (2001) 815-817. https://doi.org/10.1016/S0899-9007(01)00651-7.

[19] G.W. Winston, Oxidants and antioxidants in aquatic animals, Comp. Biochem. Physiol. Part C, Comp. 100 (1991) 173-176. https://doi.org/10.1016/0742-8413(91)90148-M.

[20] F. Shahidi, Y. Zhong, Antioxidants from marine by-products, Woodhead Publishing 
Limited, 2006. https://doi.org/10.1533/9781845692087.2.397.

[21] G. Konuray, Z. Erginkaya, Antimicrobial and antioxidant properties of pigments synthesized from microorganisms, Battle Against Microb. Pathog. Basic Sci. Technol. Adv. Educ. Programs. (2015) 27-32.

http://www.microbiology5.org/microbiology5/book/27-33.pdf.

[22] C.-Y. Ren, E.-L. Wu, E.M. Hartmann, H.-P. Zhao, Biological Mitigation of Antibiotic Resistance Gene Dissemination by Antioxidant-Producing Microorganisms in Activated Sludge Systems, Environ. Sci. Technol. (2021). https://doi.org/10.1021/acs.est.1c04641.

[23] F. Shahidi, Y. Zhong, Measurement of antioxidant activity, J. Funct. Foods. 18 (2015) 757-781. https://doi.org/10.1016/j.jff.2015.01.047.

[24] A. Torres de Pinedo, P. Peñalver, J.C. Morales, Synthesis and evaluation of new phenolic-based antioxidants: Structure-activity relationship, Food Chem. 103 (2007) 5561. https://doi.org/10.1016/j.foodchem.2006.07.026.

[25] D.D. Tshilanda, P.B. Babady, D.N.V. Onyamboko, C.M.T. Tshiongo, D.S.T. Tshibangu, K. te N. Ngbolua, P.V. Tsalu, P.T. Mpiana, Chemo-type of essential oil of Ocimum basilicum L. from DR Congo and relative in vitro antioxidant potential to the polarity of crude extracts, Asian Pac. J. Trop. Biomed. 6 (2016) 1022-1028. https://doi.org/10.1016/j.apjtb.2016.08.013.

[26] P.G. Pietta, Flavonoids as antioxidants, J. Nat. Prod. 63 (2000) 1035-1042. https://doi.org/10.1021/np9904509.

[27] A. Scalbert, I.T. Johnson, M. Saltmarsh, Polyphenols: antioxidants and beyond., Am. J. Clin. Nutr. 81 (2005) 215-217. https://doi.org/10.1093/ajcn/81.1.215s. 
[28] K.B. Pandey, S.I. Rizvi, Plant polyphenols as dietary antioxidants in human, Oxidative Med. Cell. Longev. . 2 (2009) 270-278.

[29] J. Muthukumaran, S. Srinivasan, R.S. Venkatesan, V. Ramachandran, U. Muruganathan, Syringic acid, a novel natural phenolic acid, normalizes hyperglycemia with special reference to glycoprotein components in experimental diabetic rats, J. Acute Dis. 2 (2013) 304-309. https://doi.org/10.1016/s2221-6189(13)60149-3.

[30] B. Velika, I. Kron, Antioxidant properties of benzoic acid derivatives against Superoxide radical, Free Radicals Antioxidants. 2 (2012) 62-67. https://doi.org/10.5530/ax.2012.4.11.

[31] N. Saravanan, S. Rajasankar, N. Nalini, Antioxidant effect of 2-hydroxy-4-methoxy benzoic acid on ethanol-induced hepatotoxicity in rats, J. Pharm. Pharmacol. 59 (2010) 445-453. https://doi.org/10.1211/jpp.59.3.0015.

[32] R.A. Al-Haidari, M.M. Al-Oqail, New benzoic acid derivatives from Cassia italica growing in Saudi Arabia and their antioxidant activity, Saudi Pharm. J. 28 (2020) 1112-1117. https://doi.org/10.1016/j.jsps.2020.07.012.

[33] J. Dai, R.J. Mumper, Plant phenolics: Extraction, analysis and their antioxidant and anticancer properties, Molecules. 15 (2010) 7313-7352. https://doi.org/10.3390/molecules15107313.

[34] Q. Liu, L. Luo, L. Zheng, Lignins: Biosynthesis and biological functions in plants, Int. J. Mol. Sci. 19 (2018). https://doi.org/10.3390/ijms19020335.

[35] P. Škorňa, M. Michalík, E. Klein, Gallic acid: thermodynamics of the homolytic and heterolytic phenolic $\mathrm{O}-\mathrm{H}$ bonds splitting-off, Acta Chim. Slovaca. 9 (2016) 114-123. https://doi.org/10.1515/acs-2016-0020. 
[36] B. Badhani, R. Kakkar, Influence of intrinsic and extrinsic factors on the antiradical activity of Gallic acid: a theoretical study, Struct. Chem. 29 (2018) 359-373. https://doi.org/10.1007/s11224-017-1033-9.

[37] A. Mohajeri, S.S. Asemani, Theoretical investigation on antioxidant activity of vitamins and phenolic acids for designing a novel antioxidant, J. Mol. Struct. 930 (2009) 15-20. https://doi.org/10.1016/j.molstruc.2009.04.031.

[38] Y. Shang, H. Zhou, X. Li, J. Zhou, K. Chen, Theoretical studies on the antioxidant activity of viniferifuran, New J. Chem. 43 (2019) 15736-15742. https://doi.org/10.1039/c9nj02735a.

[39] I.O. Alisi, A. Uzairu, S.E. Abechi, Molecular design of curcumin analogues with potent antioxidant properties and thermodynamic evaluation of their mechanism of free radical scavenge, Bull. Natl. Res. Cent. 44 (2020). https://doi.org/10.1186/s42269-020-00391-z.

[40] Y.Z. Zheng, G. Deng, D.F. Chen, Q. Liang, R. Guo, Z.M. Fu, Theoretical studies on the antioxidant activity of pinobanksin and its ester derivatives: Effects of the chain length and solvent, Food Chem. 240 (2018) 323-329. https://doi.org/10.1016/j.foodchem.2017.07.133.

[41] A. Vásquez-Espinal, O. Yañez, E. Osorio, C. Areche, O. García-Beltrán, L.M. Ruiz, B.K. Cassels, W. Tiznado, Theoretical Study of the Antioxidant Activity of Quercetin Oxidation Products, Front. Chem. 7 (2019) 1-10. https://doi.org/10.3389/fchem.2019.00818.

[42] M.J. Frisch, G.W. Trucks, H.B. Schlegel, G.E. Scuseria, M.A. Robb, J.R. Cheeseman, G. Scalmani, V. Barone, B. Mennucci, G.A. Petersson, Nakatsuji, M. Caricato, X. Li, H.P. Hratchian, A.F. Izmaylov, J. Bloino, G. Zheng, J.L. Sonnenberg, M. Hada, M. Ehara, K. Toyota, R. Fukuda, J. Hasegawa, M. Ishida, T. Nakajima, Y. Honda, O. Kitao, H. Nakai, 
T. Vreven, J.A.J. Montgomery, J.E. Peralta, F. Ogliaro, M. Bearpark, J.J. Heyd, E. Brothers, K.N. Kudin, V.N. Staroverov, R. Kobayashi, J. Normand, K. Raghavachari, A. Rendell, J.C. Burant, S.S. Iyengar, J. Tomasi, M. Cossi, N. Rega, J.M. Millam, M. Klene, J.E. Knox, J.B. Cross, V. Bakken, C. Adamo, J. Jaramillo, R. Gomperts, R.E. Stratmann, O. Yazyev, A.J. Austin, R. Cammi, C. Pomelli, J.W. Ochterski, R.L. Martin, K. Morokuma, V.G. Zakrzewski, G.A. Voth, P. Salvador, J.J. Dannenberg, S. Dapprich, A.D. Daniels, O. Farkas, J.B. Foresman, J. V. Ortiz, J. Cioslowski, and D.J. Fox, Gaussian 09 (C.01) inc., Wallingford CT. (2009).

[43] Y.Z. Zheng, G. Deng, Q. Liang, D.F. Chen, R. Guo, R.C. Lai, Antioxidant activity of quercetin and its glucosides from propolis: A theoretical study, Sci. Rep. 7 (2017) 1-11. https://doi.org/10.1038/s41598-017-08024-8.

[44] J. Rimarčík, V. Lukeš, E. Klein, M. Ilčin, Study of the solvent effect on the enthalpies of homolytic and heterolytic $\mathrm{N}-\mathrm{H}$ bond cleavage in p-phenylenediamine and tetracyano-pphenylenediamine, J. Mol. Struct. THEOCHEM. 952 (2010) 25-30. https://doi.org/10.1016/j.theochem.2010.04.002.

[45] J. Tomasi, B. Mennucci, R. Cammi, Quantum mechanical continuum solvation models, Chem. Rev. 105 (2005) 2999-3093. https://doi.org/10.1021/cr9904009.

[46] J. Tomasi, B. Mennucci, E. Cance, The IEF version of the PCM solvation method : an overview of a new method addressed to study molecular solutes at the QM ab initio level, 464 (1999) 211-226.

[47] C.J. Cramer, Implicit Solvation Models: Equilibria, Structure, Spectra, and Dynamics Chemical Reviews (ACS Publications), Chem. Rev. (1999). http://pubs.acs.org/doi/abs/10.1021/cr960149m\%5Cnpapers3://publication/uuid/9E41E0B 
7-0C7F-4FB4-A199-FA9D7134DB0F.

[48] G.A. Zhurko, D.. Zhurko, Chemcraft. Version 1.7 (Build 132). www.chemcraftprog.com, (n.d.).

[49] W. Humphrey, A. Dalke, K. Schulten, VMD: Visual Molecular Dynamics, J. Mol. Graph. 14 (1996) 33-38. https://www.tapbiosystems.com/tap/products/index.htm.

[50] C. Siquet, F. Paiva-Martins, J.L.F.C. Lima, S. Reis, F. Borges, Antioxidant profile of dihydroxy- and trihydroxyphenolic acids - A structure-activity relationship study, Free Radic. Res. 40 (2006) 433-442. https://doi.org/10.1080/10715760500540442.

[51] J. Contreras-García, E.R. Johnson, S. Keinan, R. Chaudret, J.P. Piquemal, D.N. Beratan, W. Yang, NCIPLOT: A program for plotting noncovalent interaction regions, J. Chem. Theory Comput. 7 (2011) 625-632. https://doi.org/10.1021/ct100641a.

[52] G. Mazzone, M. Toscano, N. Russo, Density functional predictions of antioxidant activity and UV spectral features of nasutin A, isonasutin, ellagic acid, and one of its possible derivatives, J. Agric. Food Chem. 61 (2013) 9650-9657. https://doi.org/10.1021/jf403262k.

[53] S. Hamadouche, A. Ounissi, K. Baira, N. Ouddai, M. Balsamo, A. Erto, Y. Benguerba, Theoretical evaluation of the antioxidant activity of some stilbenes using the Density Functional Theory, J. Mol. Struct. 1229 (2021) 129496.

https://doi.org/10.1016/j.molstruc.2020.129496.

[54] D. Evgeny, D. Taisa, Dissociation Energies of O - H Bonds of, 57 (2010) 1858-1866.

[55] A. Alberti, R. Amorati, M. Campredon, M. Lucarini, D. MacCiantelli, G. Pedulli, Antioxidant activity of some simple phenols present in olive oil, Acta Aliment. 38 (2009) 427-436. 
https://doi.org/10.1556/AAlim.38.2009.4.3.

[56] G. Mazzone, N. Malaj, N. Russo, M. Toscano, Density functional study of the antioxidant activity of some recently synthesized resveratrol analogues, Food Chem. 141 (2013) 2017-2024. https://doi.org/10.1016/j.foodchem.2013.05.071.

[57] G. Wang, Y. Xue, L. An, Y. Zheng, Y. Dou, L. Zhang, Y. Liu, Theoretical study on the structural and antioxidant properties of some recently synthesised 2,4,5-trimethoxy chalcones, Food Chem. 171 (2015) 89-97. https://doi.org/10.1016/j.foodchem.2014.08.106.

[58] M. Leopoldini, S.G. Chiodo, N. Russo, M. Toscano, Detailed investigation of the $\mathrm{OH}$ radical quenching by natural antioxidant caffeic acid studied by quantum mechanical models, J. Chem. Theory Comput. 7 (2011) 4218-4233. https://doi.org/10.1021/ct200572p.

[59] Y. Ma, Y. Feng, T. Diao, W. Zeng, Y. Zuo, Experimental and theoretical study on antioxidant activity of the four anthocyanins, J. Mol. Struct. 1204 (2020). https://doi.org/10.1016/j.molstruc.2019.127509.

[60] J.S. Wright, E.R. Johnson, G.A. DiLabio, Predicting the activity of phenolic antioxidants: Theoretical method, analysis of substituent effects, and application to major families of antioxidants, J. Am. Chem. Soc. 123 (2001) 1173-1183. https://doi.org/10.1021/ja002455u.

[61] J.J. Fifen, M. Nsangou, Z. Dhaouadi, O. Motapon, N. Jaidane, Solvent effects on the antioxidant activity of 3,4-dihydroxyphenylpyruvic acid: DFT and TD-DFT studies, Comput. Theor. Chem. 966 (2011) 232-243. https://doi.org/10.1016/j.comptc.2011.03.006. 
[62] J. Chen, J. Yang, L. Ma, J. Li, N. Shahzad, C.K. Kim, Structure-antioxidant activity relationship of methoxy, phenolic hydroxyl, and carboxylic acid groups of phenolic acids, (2020) 1-9.

[63] Y. Xue, Y. Zheng, L. An, Y. Dou, Y. Liu, Density functional theory study of the structureantioxidant activity of polyphenolic deoxybenzoins, Food Chem. 151 (2014) 198-206. https://doi.org/10.1016/j.foodchem.2013.11.064.

[64] A. Urbaniak, M. Szelag, M. Molski, Theoretical investigation of stereochemistry and solvent influence on antioxidant activity of ferulic acid, Comput. Theor. Chem. 1012 (2013) 33-40. https://doi.org/10.1016/j.comptc.2013.02.018.

[65] A. Ali, M. Khalid, S. Abid, M.N. Tahir, J. Iqbal, M. Ashfaq, F. Kanwal, C. Lu, M.F.U. Rehman, Green synthesis, SC-XRD, non-covalent interactive potential and electronic communication via DFT exploration of pyridine-based hydrazone, Crystals. 10 (2020) 120. https://doi.org/10.3390/cryst10090778. 
